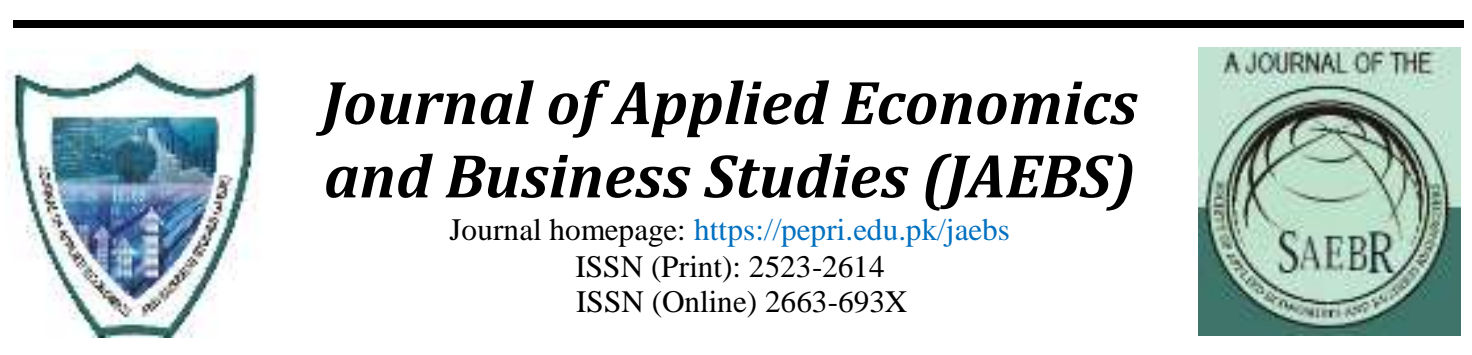

\title{
Do Regulations on Smoking Limit Cigarette Demand? An Empirical Evidence from Pakistan
}

\author{
Assad Ullah Khan ${ }^{1 *}$ and Anwar Shah ${ }^{2}$ \\ ${ }^{1}$ Lecturer at University of Science \& Technology, Bannu, KPK \\ ${ }^{2}$ Associate Professor at Quaid-i- Azam University (QAU), Islamabad
}

\begin{abstract}
Enacting Ordinance No LXXIV 2002, Pakistan has developed crucial antitobacco policies in the last two decades. We, therefore, examine in this paper effects of both price (cigarette taxation) and non-price (public regulations on cigarette smoking) anti-tobacco policies on cigarette demand. To accomplish this objective, we examine the short and long run dynamics of cigarette demand in Pakistan using auto-regressive distributed lag (ARDL) estimator covering the period 1981-2018 (annual observations). The study compares price elasticity estimated with and without regulations on cigarette smoking. The result obtained shows that when price increases by $10 \%$, cigarette consumption decreases by $5 \%$ in the short run while it decreases by $6.9 \%$ in the long run. This finding confirms that cigarette demand model, in Pakistan, is in-elastic. More interestingly, the study finds that non-price regulations on smoking and cigarette demand have negative and statistically significant association. This finding confirms that non-price regulations influences the long-term dynamics of cigarette smoking in Pakistan. Furthermore, we obtain low price elasticity with non-price regulations and high price elasticity without non-price regulations while estimating cigarette demand equation. This empirical result is an evident of the fact that estimated cigarette price elasticity without incorporating nonprice regulations into the demand model, are upward biased. The study therefore, concludes that smoking regulation policy based on overstated cigarette price elasticity would produce ambiguous outcomes. Hence, relying only on cigarette taxation (price policy) to regulate cigarette smoking would not produce desirable outcome. In addition, university education is positively and significantly associated with cigarette consumption. This finding show that our university education do not properly convey anti-smoking message to students. To reduce cigarette smoking, Pakistan will have to implement stronger, more comprehensive and better enforced non-price regulations along with taxes on cigarettes.
\end{abstract}

*asadwazir82@yahoo.com

Keywords

Smoking Regulations;

Cigarette

Demand;

Cigarette

Price

Elasticity;

Cigarette

advertisement, promotion;

Pakistan

Tobacco

Board (PTB); ARDL; ECM 


\section{Introduction}

Cigarette smoking is harmful to health of all individuals (smokers as well as nonsmokers). Every year cigarette smoking ( the most commonly used form of tobacco) causes more than 8 million deaths worldwide due to lung cancer, cardiovascular diseases and hypertension (WHO, 2020). To get rid of the menace of cigarette smoking, the WHO Framework Convention for Tobacco Control (FCTC) advocates imposition of high taxes on cigarette production, as well as other non-price regulations on smoking such as restriction on cigarette advertisement and promotion, sales to minors, and prominent warning on packs of cigarettes (FCTC, 2015). This report calls for government, policy makers and researchers to design policies that raises cigarette prices through taxation, restrict cigarette smoking in public places so that demand for cigarette may be reduced substantially. In addition, restricting cigarette advertisement and promotion, placing health warning on cigarette packages are also helpful in limiting cigarette demand. Since, it is now generally believed that cigarette smoking is the single largest preventable cause of premature death. By $2020,70 \%$ of those killed by tobacco will be from developing economies of the world (Jha \& Chaloupka, 1999).

In most develop countries, the prevalence of smoking is declining over time and so are the tobacco related illness and deaths. Unfortunately, in developing countries like Pakistan, the trend of smoking increases gradually (Hana Ross \& Al-Sadat, 2007; Jha $\&$ Chaloupka, 1999). World Health Organization (WHO) reported that, in Pakistan, 31.8 $\%$ male, $5.8 \%$ female, and $19.1 \%$ adults are consuming tobacco products. And among them, $17.9 \%$ male, $1 \%$ female and $9.6 \%$ adults are smoking cigarettes (WHO, 2015).

Given the high prevalence of smoking and the resulting premature death and illness, it becomes imperative for the government of Pakistan to intervene in the market for tobacco. Literature suggests that taxation is the most useful strategy to reduce the use of tobacco. Various studies have indicated that cigarette taxation and demand are negatively associated (see: Chaloupka \& Warner, 2000; Graham, 2013; Marzioni et al., 2020; Randell, 2018; Stoklosa et al., 2016; Teixeira, 2018). Literature also finds that compare to develop countries, cigarette elasticity is high in low and middle income countries. For example, Walbeek (2005) shows that studies from developed countries obtained price elasticity of cigarette consumption at around -0.4 while it lies in the range of -0.4 to -0.8 for developing economies. This is supported by John, (2008) showing that price elasticity estimates of cigarette, beedi (tobacco rolled in dry leaves) and leaf tobacco in India lie in the range between -0.4 to -0.9. Similarly, evidence from advance countries shows that cigarette consumption reduces by $2.5 \%$ to $5 \%$ in response to a $10 \%$ increase in price(Chaloupka \& Warner, 2000b). In addition, we also find varied estimates of cigarette price elasticities from studies conducted in Pakistan. For instance, Mushtaq et al.,( 2011) finds price elasticity of smoking for Pakistan greater than unity that is, -1.17. However, Burki et al., (2013) estimated price elasticity is less than unity, that is, it is equal to -0.58 . 
Journal of Applied Economics and Business Studies, Volume. 4, Issue 4 (2020) 161-186 https://doi.org/10.34260/jaebs.448

A detail review of literature on cigarette consumption suggests the following research gaps with reference to cigarette price elasticity and non-price regulations on smoking. First, studies on cigarette demand, in Pakistan, have estimated price elasticity with reference to taxation or price of cigarette only. For example Mushtaq et al.,(2011) regress cigarette consumption on cigarette price and income only. Resultantly, the price elasticity found is greater than unity. Similarly, studies from South Asian region provide price elasticities to be greater than unity. For example, ( Guindon et al., 2011) for India (-1.03); Nayab et al., (2018) for Pakistan (-1.06); Del Carmen et al., (2018) for Bangladesh (-1.3). These studies have completely ignored the role of non-price regulations in reducing cigarette demand. We therefore, deduce that the estimated cigarette price elasticities owing to the cigarette prices only could be upward biased (over-stated).

Second, in Pakistan the tier system of federal tax on cigarette is highly complex. The complexity arises when government increases tax on high brands of cigarettes, smokers shift to other low brands or low price cigarettes. This results in increasing volume of cigarette smoking as low brands cigarettes are afforded by large number of people. This high tax may also give rise to illicit cigarettes production and increasing demand for unreported cigarettes(Nayab et al., 2018; SPDC, 2018). As non-price regulations on smoking like ban on cigarette advertisement and promotion and placing health warning on cigarette packets are generally applicable on all brands of cigarette. We therefore, believe that non-price regulations on smoking along with cigarette taxes will prove highly significant in reducing cigarette smoking.

In this line, one can see a number of developments in Pakistan tobacco control policies since the promulgation of Ordinance No LXXIV 2002. The ordinance includes restrictions on smoking in public places, restriction on tobacco companies' marketing, and placing health warnings on cigarette packages (Nayab et al., 2018). Pakistan, became a member of WHO FCTC in 2004, since then the government issued a number of Ordinances and SROs (Statutory Regulatory Orders) to regulate cigarette smoking(Burki et al., 2013). However, tobacco control policies in Pakistan are hardly monitored and poorly implemented. Beside, in Pakistan, we find very little evidence on the effectiveness of non-price regulations in cigarette demand models. Literature gives a varying range of estimates of the impact of increasing prices through taxation on cigarette consumption. Extensive demand models for cigarette have been empirically examined in studies from developed and developing countries as well. Beside price effect, these models of cigarette demand have introduced government regulation on smoking like, restrictions on cigarette smoking in work place and or public place, banning cigarette advertising and promotion, health warning on cigarette packets and restriction on selling cigarettes to minors, all of which could play a significant role in reducing demand for cigarette. In Pakistan, one can find very little research studies that have examined the effect of regulations on cigarette smoking. This study attempts to empirically examine the effects of price as well as non-price cigarette regulations on the 
demand for cigarette in Pakistan. More specifically, the study test the hypothesis that do non-price public restrictions on cigarette smoking are helpful (significant) in limiting cigarette demand? To see more detail analysis of cigarette demand, sections of the study are given as under.

Section 2 provides relevant literature on cigarette demand analysis. In Section 3, we have presented a brief overview of cigarette production, taxation and regulations on smoking in Pakistan. Section 4 gives understanding of econometric model of cigarette demand. This section explain ARDL estimator including a dummy variable for regulation on smoking. Section 5 presents empirical estimates of the coefficients of variables included in the cigarette demand model. Suggestions and policy implications are reported in the final section.

\section{Literature Review}

Empirical findings of the studies that have analyzed cigarette demand, gives inconclusive results. These studies give varying estimates of cigarette price elasticities owing to differences in data and estimation techniques. For instance, Warner (1981) obtain price elasticity of -0.37 by conducting aggregate time series data during the period 1947 to 1978. Similarly, using ridge regression techniques, Fuji (1980) conduct an empirical study to find numerical values of the coefficients of cigarette demand equation. The empirical findings of the study show negative price elasticity of -0.47 while positive income elasticity of 0.22 . A recent study conducted by Cetin (2017) confirms that regulation on cigarette smoking matters in the estimation of cigarette elasticity. The study apply OLS estimation method to monthly and quarterly data and observe that whether taxation and regulations have affected cigarette demand. Empirical findings of the study confirms that pre-and post-taxation and regulations elasticities are different.

There seems a policy dilemma of the kind that whether additional taxation on cigarette is desirable. On the one hand, cigarette consumption is generally considered an evil which causes serious diseases like lung cancer, heart disease, brain strokes and other skin problems. On the contrary, cigarette production and sale is a source of revenue for the national ex-checquer. Hu \& Mao (2002) address this issue by examining the impact of cigarette taxation on cigarette demand. The study suggests additional duty on cigarette smoking to attain good health and economic gain. More specifically, simulation of the results show that when cigarette elasticity is -0.54 , cigarette consumption would fall by 4.74 billion packets to a tax increase of 40 percent. This increase in taxation would add additional amount of 24.74 billion (yuan) to the revenue and would save lives of 1.44 to 2.16 million people. In addition, as a result of taxation, addition to the national ex checquer would be larger than total industrial and farmer's income loss. Similarly, Hana Ross \& Al-Sadat (2007) confirms that taxation reduces cigarette consumption as well as tobacco- related deaths. In addition, tobacco taxation is also a source of increasing revenue for the government. Applying error correction 
Journal of Applied Economics and Business Studies, Volume. 4, Issue 4 (2020) 161-186 https://doi.org/10.34260/jaebs.448

method to the time series data collected during 1990-2004, the study finds tax elasticity of -0.57 and income elasticity as 0.08 . Simulation of the results indicate that cigarette smoking falls by $3.37 \%$ when cigarette tax is increased by 0.40 ringgit (Malaysian currency) on a packet of cigarette. This increase in cigarette tax would further add $20.8 \%$ to the government revenue.

Beside excise tax on cigarettes (prices), many studies have analyzed the role of nonprice government regulation, including restrictions on cigarette advertisement and promotion, health warning on cigarette packages, information campaigns, and clean indoor air restrictions. For example, it has been remained a controversial issue that whether or not advertising affects tobacco consumption. Government, health-care officials and tobacco control advocates suggest that advertisement and tobacco consumption are positively associated and banning advertisement can reduce tobacco use substantially. On the contrary, tobacco industry argue that advertisement does not encourage cigarette smoking but it only increases the relative importance of a particular brand of cigarette in the market. In this line, literature provides rich empirical evidence to highlight the link between cigarette advertisement and cigarette smoking. For example, Saffer \& Chaloupka (2000), using data on 22 OECD countries during the period 1984-1992, examines the relationship between restrictions on tobacco advertisement and tobacco use. The study concludes that tobacco advertisement and tobacco consumption varies positively. Moreover, result of the study shows that a complete set of restriction on tobacco advertisement can reduce tobacco use substantially. On the contrary, a limited or weak ban on tobacco advertisement will have little or no effect at all. The result further indicates that in case all OECD countries had used complete restrictions, it will reduces $5.4 \%$ and $7.4 \%$ tobacco and cigarette use respectively. Similarly, (Wasserman et al., (1991) estimates a generalized linear model to empirically estimate demand for cigarette of adult and teenage. The results show that adult and teenage price elasticity are almost equal in magnitude. Adult demand indicates an unstable price elasticity ranging from 0.06 in 1970 to -0.23 in 1985 . Furthermore, the study shows that public restrictions on smoking have statistically significant effect on both demand models for adult and teenage.

Unlike Saffer \& Chaloupka (2000), Nelson (2003) analysis of tobacco demands finds that restrictions on tobacco advertisement have no effect on tobacco use. The study identify that prior studies suffered from two problems. First, these studies ignore the fact that restriction on tobacco advertisement and tobacco use are simultaneously determined. That is, countries had legislated advertising bans only when tobacco consumption had fallen substantially. Second, Nelson (2003) indicates that in crosscountry studies, almost all countries suffer from auto-correlation. Therefore, the study empirically analyze a simultaneous equations and treating restriction on tobacco advertisement as endogenous variable.

Beside, literature also indicates that cigarette demand is more sensitive to price, income and non-price smoking restrictions (like health warning, media bans, bans on 
smoking in public place ) in developing countries relative to developed countries of the world. One possible explanation for this could be larger price elasticity of cigarette demand in developing economy. For example, Walbeek (2005) confirms this statement by arguing that almost all researchers are of the view that cigarette elasticity for developed counties equals -0.4 while it lies in the range of -0.4 to -0.8 for developing economies. Another reason could be that individuals in developing countries have low education levels which in turn may be the reason for little or no understanding of the negative health consequences of smoking. Empirical studies from advance economies indicates that only comprehensive bans on advertisement play a role in reducing cigarette demand. The reason could be that in case of limited bans the industry may be able to shift advertisement away from the banned media towards those which is yet free from such bans. However, this may not be the case for developing economies. For instance, Blecher (2008) finds very interesting result for developing economies, that is, both comprehensive as well as weak bans play an important role in limiting cigarette demand. The study examines cross countries demand equations to see whether restriction on advertisement and cigarette smoking are correlated. Data set comprising 51 countries (21 developed; 30 developing) during the period 1990 to 2005 was collected. The empirical result for developing countries of the study shows that both comprehensive and weak ban are effective in reducing cigarette consumption. In addition, comparative result of comprehensive and weak ban indicates that the former have a far greater negative influence $(23.5 \%)$ than the later (13.6\%).

Unfortunately, developing economies lacks effective implementation of tobacco control polices due to economic benefits in the form of tobacco agriculture, manufacture, and tax revenue. However, these economic benefits to the farmer and industry are very low compared to the harms caused by tobacco consumption. Keeping in view the rising social and healthcare costs of tobacco consumption, researchers in Pakistan have attempted to empirically estimate price elasticity of tobacco demand. For example, (Mushtaq et al (2011) empirically estimates price elasticity of cigarette demand in Pakistan. Using ARDL estimation techniques to the annual data from 1981 to 2009 , the study finds that increasing cigarette taxation and therefore prices are helpful in limiting cigarette smoking. More specifically, the study result shows that cigarette smoking falls by $4.8 \%$ in the short-run and $11.7 \%$ in the long-run to a $10 \%$ increase in cigarette taxes (cigarette prices).

Ahsan et al. (2015) conduct cross-sectional study to see whether, in Pakistan, health warning on a packet of cigarette are effective in reducing smoking. For this purpose, self-structured questionnaire was distributed in Karachi from July to October 2014. The result indicates that out of total $1500,1330(88.7 \%)$ did notice health warnings on cigarette packages. Moreover, the study adds that $730(54.8 \%)$ responded positively that pictorial warnings are more effective in reducing cigarette consumption. Finally, the study suggest that to reduce cigarette consumption significantly, the government of Pakistan should make the graphical warnings more clear and prominent. A similar study 
Journal of Applied Economics and Business Studies, Volume. 4, Issue 4 (2020) 161-186 https://doi.org/10.34260/jaebs.448

conducted by Rasool et al. (2011) finds that compliance of anti-smoking regulations by cigarette industry for showing health warning is $39 \%$ which is very low than desired. Cigarette selling shops were observed in Abbottabad with the aim to determine total cigarette brand availability and their compliance of anti-smoking regulations. The results show that total 18 cigarette brands are available in Abbottabad city. In addition, the study finds that $38.4 \%$ varieties of cigarette brands carry health warnings on cigarette packets. Mostly cigarette customers are between 20-40 years of age and buy cigarette brands that do not carry health warnings. The study suggest to the Ministry of Health $(\mathrm{MoH})$ for ensuring health warnings on cigarette packages so that smokers be aware of negative health consequences of smoking.

Literature has identified various social and environmental factors responsible for smoking initiation. These factors include peer pressure, domestic and occupational stress relief, nicotine dependency, parental smoking, media influence, easy availability and affordability of cigarette. In this line, Nizami et al. (2011) distributes a questionnaire among 170 participants with the aim to determine factors contributing to smoking initiation and propagation. The study finds occupational stress relief mainly responsible for cigarette smoking followed by peer pressure. Further, the study finds that although stress or nicotine dependency appears to be a factor of cigarette smoking in the middle age, however, smoking initiation is mainly due to peer pressure at a young age. Another study conducted by Alam et al., (2008) investigates the socio-economic and demographic determinants of tobacco use during 2004 to 2005. A cross-sectional survey based on self-structured questionnaire was carried out in the Rawalpindi district of Pakistan. Using multi-stage cluster sampling with rural and urban stratification, a total of 1018 respondents (1038 Rural; 980 Urban) were face to face interviewed. Result of the cross sectional analysis indicates that $16.5 \%$ of the respondents $(33 \%$ male; $4.7 \%$ women) regularly uses tobacco. The study also finds cigarette smoking as the most commonly used form of tobacco $(68.5 \%)$ followed by oral tobacco $(13.5 \%)$. As regard to the demographic factors, the study finds that rural area, male and low educational status all have positive association with tobacco consumption.

Literature gives mixed and inconclusive results concerning the effect of taxes (cigarette price) and regulations on cigarette smoking (non-price public restrictions) on cigarette demand. Few studies have ignored the effect of non-price regulations on smoking, therefore, their estimated price elasticity is more than unity. Others have only focused on individual cigarette regulation like, media ban on cigarette advertisement and or placing warning on a packet of cigarette. In Pakistan, we find very little empirical evidence which has analyzed the role of non-price regulations on cigarette smoking. We therefore, address this issue in detail. In this line, we attempt to estimate both the effect of price as well as non-price regulations on cigarette consumption. In the next section, we present a brief history of taxation and regulations on cigarette smoking in Pakistan and compare these with the estimates of our model.

\section{Overview of Cigarette Production, Taxation and Regulations in Pakistan}


One reason for the growing prevalence of smoking in Pakistan might be the cheap tobacco prices and increasing affordability of cigarettes. Affordability of cigarettes in Pakistan, as measured by the ratio of average cigarette pack price to per capita income, was low in the early 1990s as real income was falling more rapidly. This reduction in affordability of cigarettes contributed to low cigarette consumption during this period. However, rapid increase in the real income and thereby increasing affordability might be a reason for the rise in cigarette consumption during the late 1990s (Burki et al., 2013). Beside, in Pakistan, the Federal Excise Duty (FED) on cigarette is highly complex, imposing different amount of taxes on the basis of retail prices. For example more recently in 2017, the re-introduction of three tier tax structure on cigarette gave rise to the increasing sale of low-brand cigarettes in the country (Nayab et al., 2018; SPDC, 2018).

Figure 1, provides trends of the domestic production of cigarettes from 1981 to 2018. The graph shows that domestic production increases from 35.8 billion sticks in 1980-81 to as high as 75.6 billion sticks in 2008-09. However, from 2009 onwards cigarette production show a declining trend till 2016-17, reaching to a level as low as 34.3 billion sticks. After the declining trend, the production of cigarette picked up to 59 billion sticks in 2017-18. This surge in the production of cigarette was mainly due to the re-introduction of third tier excise duty for low-priced brands. The FBR officials and the tobacco industry defended this move by arguing that the third tier excise duty will prove fruitful at curbing the illicit cigarette production. However, in reality a loss of 36 billion (Pakistan rupees) occur to the revenue department as a result of introducing three tier excise duty on cigarettes. This loss occurred mainly because cigarette industries in Pakistan shifted high tax brand cigarettes to low tax or low price brand cigarettes. This brand shifting of the cigarette companies resulted in the reduction of FED on several brands of cigarette from Rs.32.98 to Rs.16 in the fiscal year 2017-18 (Nayab et al., 2018).

Figure 1 Production of Cigarette in Millions

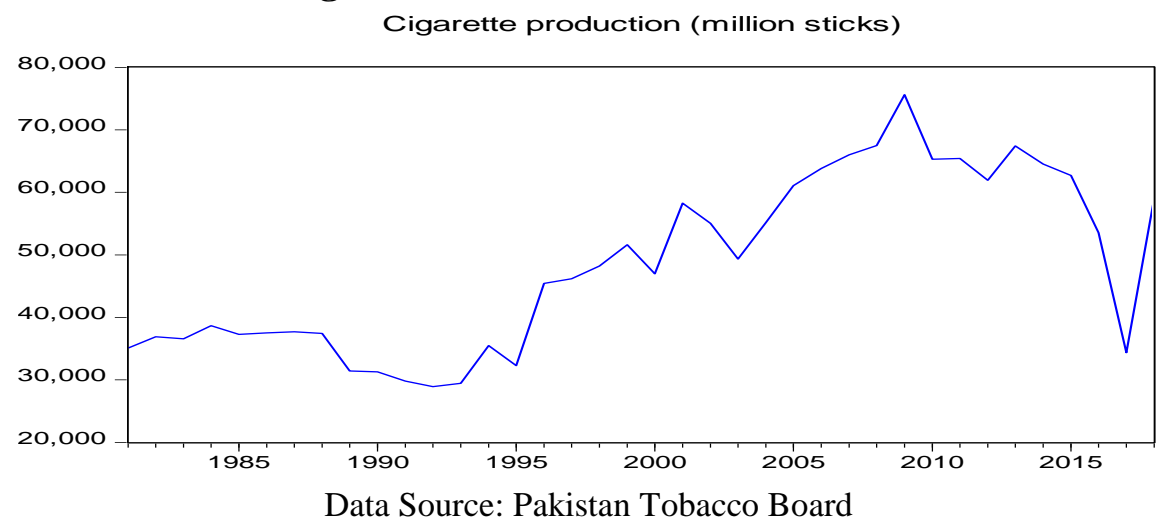

Below, table 3.1 show the actual trend of cigarette consumption, average prices of cigarettes, and the tax revenue collected by the government of Pakistan during the period 2015-18.

Table 3.1 Cig Consumption, Taxes and Prices (2015-2018) 
Journal of Applied Economics and Business Studies, Volume. 4, Issue 4 (2020) 161-186 https://doi.org/10.34260/jaebs.448

\begin{tabular}{|c|c|c|c|}
\hline Year & $\begin{array}{c}\text { Cig. Consumption (million } \\
\text { sticks) }\end{array}$ & $\begin{array}{c}\text { Total Taxes (Million } \\
\text { Rs) }\end{array}$ & Cig. Price/packet \\
\hline 2015 & 62687.24 & 102890 & 45.85 \\
\hline 2016 & 53545.23 & 114202 & 57.75 \\
\hline 2017 & 34350.92 & 83693 & 65.44 \\
\hline 2018 & 59065.35 & 87450 & 50.86 \\
\hline
\end{tabular}

Data Source: Pakistan Tobacco Board.

Cigarette prices per packet have been taken from Economic Survey of Pakistan.

As evident from the table, average prices of a packet of 10 cigarettes have declined from PKR 65.44 to PKR 50.86 during the period 2017-18. However, volume of cigarette production increased from 34 billion sticks to 59 billion during this period. The government regain its lost revenue nearly equal to Rs. 3757 million. However, statistics indicate that contrary to the government's claim, the three tier structure failed to generate additional tax revenue even though cigarette production has increased considerably.

Beside taxation, non-price regulations on smoking also play a significant role in decreasing cigarette consumption. These regulations includes printing of health warnings on cigarette packages, prohibition of smoking in enclosed places, ban on cigarette advertising and promotion, restrictions on cigarette sale near educational institutions and sale to minors. Although, the legislation of tobacco use in Pakistan can be traced with the introduction of the "Motor Vehicle Ordinance" in 1965 and later Cigarette (Printing of Warning) Ordinance No. LXXIII, 1979. However, due to high literacy rate in the country, these warning ordinances did not effectively convey the message of negative health consequences of smoking. Later on, in 2002, the government of Pakistan issued a comprehensive health ordinance "Restrict Smoking in Indoor Places and Health Warning Ordinance No. LXXIV". The ordinance restrict smoking in indoor work places such as schools, hospitals, transport and all other government buildings and offices. It bans advertisement and promotion of tobacco, restrict sales to children and prohibits sales in the premises of academic institutions (Burki et al., 2013; Nayab et al., 2018).

In this line, Pakistan signed the WHO FCTC in 2004, which resulted in quite significant improvement in tobacco regulation policies. To fulfill its obligations required by FCTC, the country issued various Statutory Rules and Orders (SROs) to amend and further regulate production and consumption of tobacco. For example, the general label warning of 1979 ordinance "warning: smoking is injurious to health" was replaced in 2002 with more specific and effective health warning that "tobacco causes cancer and heart diseases". Later, a 2010 SROs called for the size (top $40 \%$ of the front and back) and rotation of the text warnings. More recently, the warning label was further strengthen by a 2018 SROs which requires 50\% pictorial warning on both sides of cigarette packages. 
Similarly, Health Ordinance No. LXXIV, 2002 prohibits smoking in government places, job places, and transport vehicles. This restriction was relaxed by 2008 SRO that allowed for specifying special smoking rooms at all government places and or job places except educational institutions and transport services. However, the controversial 2008 SRO was rolled back through another SRO issued in 2009, requiring all places of public interest $100 \%$ free of cigarette smoking. In the same manner, Ordinance LXXIV, 2002 contains some weak restrictions regarding cigarette advertising, promotion and sponsorship. These restrictions were strengthen by a 2007 SRO that provides guidelines for tobacco products advertisement. For example, it further restrict the times during which advertisement was allowed in television. In addition, the SRO banes bill board advertisement, and limit the size of tobacco advertisement in print media. Later, a 2009 SRO further amends these tobacco advertisement guidelines by restricting tobacco companies from distributing free samples of cigarette packages, and other promotional discounts. It also restrict tobacco company sponsorship of events like, sports, dramas and movies.

Empirical evidence from advance economies indicates that only strong and comprehensive tobacco regulation policies can play a significant role in decreasing tobacco consumption while weak policies will have no or very little impact on tobacco consumption. However, evidence from developing economies demonstrates that even weak tobacco control policies play a role in reducing tobacco use (Saffer \& Chaloupka, 2000). The statistical data of this paper shows that since 2009, cigarette consumption in Pakistan have declined from 75 billion sticks to as low as 34 billion sticks in 2017. This demonstrates that from the last two decades, by strengthening its tobacco control policies, cigarette consumption in Pakistan have declined significantly. However, with the introduction of third tier excise tax in 2017, which lowered cigarette prices of low brand, cigarette consumption picked up again reaching to 59 billion sticks in 2018 . Therefore, to reduce cigarette consumption, Pakistan will have to enact uniform excise taxation as well as implement stronger, comprehensive and better enforced non-price smoking regulations. In this line, this study is an attempt to see whether the adoption of non-price smoking regulations play a significant role in reducing cigarette smoking. In the next section, we develop econometric model which is best capable for modeling taxation and smoking regulations on cigarette consumption.

\section{Methodological Framework}

\subsection{Theoretical Model}

The utility function of our representative smokers is given by

$$
U=U(Q, X, E)
$$

Subject to constraint $P_{1} Q+P_{2} X=M$ where $\mathrm{Q}$ indicates number of cigarettes consumed, $\mathrm{X}$ stands for baskets of all other market goods, E shows education level, $P_{1}$ indicates cigarette prices and $P_{2}$ prices of all other goods, $M$ shows nominal money 
Journal of Applied Economics and Business Studies, Volume. 4, Issue 4 (2020) 161-186 https://doi.org/10.34260/jaebs.448

income (Yuanliang \& Zongyi, 2005). Assuming that individual's educational level is constant, then the following Lagrange Function is maximized:

$$
\max L=U(Q, X, \bar{E})+\lambda\left(M-P_{1} Q-P_{2} X\right)
$$

Taking first partial derivatives with respect to $Q, X$ and $\lambda$ respectively, we obtain

$$
\begin{array}{r}
U_{Q}-P_{1}=0 \\
U_{X}-P_{2}=0 \\
M-P_{1} Q-P_{2} X=0
\end{array}
$$

Solving equations (3), (4) and (5) respectively, we get optimal quantity of endogenous variables $Q$ and $X$ given as under

$$
\begin{aligned}
& Q^{*}=Q^{*}\left(P_{1} P_{2} E M\right) \\
& X^{*}=X^{*}\left(P_{2} P_{1} E M\right)
\end{aligned}
$$

Substituting optimal quantities $Q^{*}$ and $X^{*}$ into the objective function (1), we obtain

$$
U^{*}\left(P_{1} P_{2} E M\right)=U\left(Q^{*}\left(P_{1} P_{2} E M\right), X^{*}\left(P_{1} P_{2} E M\right)\right.
$$

Equation (7) is the indirect utility function, showing maximum value of the utility that an individual derives from optimal consumption of cigarettes and all other basket of goods. To know how educational level and cigarette consumption are related, consider the dual objective function given as under:

$$
Z(Q, E)=U(Q, E)-U^{*}(E)
$$

Differentiating equation (8) with respect to ' $W$ ' and solving we get,

$$
U_{E}=U_{E}^{*}
$$

Since we know that marginal utility of education is again a function of education, therefore in the manner of equation (7), equation (9) can be written as under:

$$
U_{E}^{*}(E)=U_{E}\left(Q^{*}(E), E\right)
$$

In view of the relationship between cigarette consumption and educational level, two hypothesis can be formulated. That is,

1) The consumer thinks that education reduces the marginal utility of cigarette consumption and thereby increase his/her total utility

2) With the increase of education, cigarette consumption will increase

To derive the former hypothesis, we optimize (maximize) equation (8) as under:

$$
\begin{aligned}
& Z_{E}=U_{E}-U_{E}^{*}=0 \\
& Z_{E E}=U_{E E}-U_{E E}^{*}<0
\end{aligned}
$$

Therefore, 


$$
U_{E E}<U_{E E}^{*}
$$

Now by differentiating both sides of equation (10) with respect to ' $E$ ' we get,

$$
U_{E E}^{*}=U_{E Q} \frac{\partial Q}{\partial E}+U_{E E}
$$

By utilizing equation (11), the above equation can be written as

$$
U_{E Q} \frac{\partial Q}{\partial E}>0
$$

We know that with the increase of education, marginal utility of cigarette consumption decreases, hence $U_{E Q}<0$ and therefore for equation (12) to hold $\frac{\partial Q^{*}}{\partial E}<0$. This clearly indicates that with the increase of educational level cigarette consumption will decrease.

To prove the second hypothesis, we minimize the function given by equation (8) as under:

$$
\begin{aligned}
& Z_{E}=U_{E}-U_{E}^{*}=0 \\
& Z_{E E}=U_{E E}-U_{E E}^{*}>0
\end{aligned}
$$

Therefore,

$$
U_{E E}>U_{E E}^{*}
$$

$$
\begin{gathered}
U_{E E}^{*}=U_{E Q} \frac{\partial Q}{\partial E}+U_{E E} \\
U_{E Q} \frac{\partial Q}{\partial E}<0
\end{gathered}
$$

We know that with the increase of education, marginal utility of cigarette consumption decreases, hence $U_{E Q}<0$ and therefore for equation (12) to hold $\frac{\partial Q^{*}}{\partial E}>0$. This clearly indicates educational level increase cigarette consumption. Theoretical model gives inconclusive result about how educational level is associated with the cigarette consumption. In the next section of the study we therefore, empirically analyze the relationship among cigarette prices, regulation on smoking, educational level and cigarette consumption (Yuanliang \& Zongyi, 2005).

\subsection{Empirical Model}

The study follows the framework in Mushtaq et al. (2011) which examines the effects of price and income on cigarette consumption. However, the study seems to have missed important variables which can significantly affect cigarette demand. It might be 
Journal of Applied Economics and Business Studies, Volume. 4, Issue 4 (2020) 161-186 https://doi.org/10.34260/jaebs.448

the reason for the high cigarette price elasticity (greater than unity) obtained in the study. We, therefore also include regulations on smoking as a controlled variable to accurately measure price elasticity and examine whether, in Pakistan, regulations on smoking play additional role in reducing cigarette smoking. In equation 1, we show that cigarette consumption depends on cigarette price, real income and regulations on cigarette smoking.

cigarette consumption $=f($ cig $\cdot$ prices, inocme, regulations $)$

Data related to cigarette production, prices, gross domestic product (GDP), excise taxes and regulations on smoking were obtained from domestic and international institutions. More specifically, data on cigarette production, exports and imports were obtained from Pakistan Tobacco Board (PTB). Cigarette consumption was calculated by subtracting net cigarette exports from cigarette production. Cigarette prices data used in the analysis for each year, were the average prices (average prices of 17 centers of one particular brand of cigarette) of a package of cigarette having 10 cigarettes. Cigarette prices data were received from Economic Survey of Pakistan 20017-18. Real Gross Domestic Product per Capita (Real GDP per Capita) was defined by dividing real GDP on population (15 years or older). World Development Indicator (WDI) gives data for Real GDP per capita. Government of Pakistan issued an ordinance titled ORDINANCE No LXXIV, 2002. This ordinance provides for restriction of tobacco and cigarette smoking in indoor places, job places and public transport vehicles. The ordinance also prohibits advertising and promotion of cigarette, sale to minor, and distribution near educational institutions. Hence, to examine the effect of regulations on smoking, the study introduces a dummy variable into the regression equation. The binary variable is taking 1 value for the period 2002 and onwards till 2018 and zero otherwise. In the next step of estimation, we includes all the relevant SROs that restrict cigarette smoking. Furthermore, the study includes enrollment in primary school and university education to proxy awareness against anti-smoking behavior.

We conduct cigarette demand analysis, using aggregate time series data on macroeconomic variables from 1981 to 2018. The study estimates the effects of cigarette prices, real income and regulations on smoking on cigarette demand. In accordance with the economic theory, cigarette consumption was taken as a function of cigarette prices, real income and regulation on smoking. More specifically, we estimate the following cigarette demand model:

$$
\ln Q_{t}=\beta_{0}+\beta_{1} \ln P_{t}+\beta_{2} \ln Y_{t}+\beta_{3} \operatorname{Re} g+\varepsilon_{t}
$$

Where $Q_{t}$ is the quantity (millions of cigarette sticks) demand and or consumed in time period (year) $t, P_{t}$ is the average price of 17 centers of a particular brand of cigarette in time period $t, Y_{t}$ is GDP per capita in time period $t$, 'Reg' is a dummy variable, taking 1 value for regulation on smoking for years 2002 to 2018 and 0 (zero) otherwise, and $\varepsilon_{t}$ is the random disturbance or white noise process. 
To produce short-run and long-run cigarette elasticities, the study apply AutoRegressive Distributive Lag (ARDL) co-integration method. This estimation method is used due to its several advantages. First, ARDL method can be applied even though data series have different order of integrations. That is, Pesaran \& Pesaran, (1997) argued that ARDL method can be used even if various series are integrated of order zero $\mathrm{I}(0)$ or one I(1). However, if data series are integrated of order I(2) or above, the estimator thus obtained would not be valid (Ouattara, 2004). In addition, in case of simultaneity, ARDL gives valid estimation of the coefficients. This is most relevant as Nelson (2003) points out that regulation on smoking and cigarette smoking are simultaneously determined. That is, governments suggest restriction on cigarette smoking only when reduction in cigarette demand has already been observed. Moreover, H. Pesaran \& Shin, (1999) noted that in case of small sample like ours (38 annual observations), ARDL estimation method produce true as well as consistent parameters compare to Johansen and Juselius's co integration techniques. Therefore, this study uses ARDL estimation method for cigarette demand analysis.

The study specify ARDL equation as under:

$\Delta \ln C_{t}=\alpha_{0}+\alpha_{1} \ln C_{t-1}+\alpha_{2} \ln P_{t-1}+\alpha_{3} \operatorname{Re} g+\sum_{i=1}^{q} \lambda_{1} \Delta \ln C_{t-i}+\sum_{i=0}^{p} \lambda_{2} \Delta \ln P_{t-i}+\varepsilon_{t}$

In equation (2), $\alpha_{1}$ and $\alpha_{2}$ show long-run association of variables while $\lambda_{1}, \lambda_{2}$ captures immediate or short-run impacts of variables on cigarette consumption. In addition, the coefficient $\alpha_{3}$ indicates the effect of smoking regulations on cigarette demand. For complete analysis of cigarette demand, using ARDL estimation, following steps are required. First, to see whether co-integration exist, the study applies F-test to the above equation (3). Our null hypothesis is $H_{0}: \alpha_{1}=\alpha_{2}=\alpha_{3}=0$. This shows that there is no co-integration. On the contrary, our alternative hypothesis is $H_{1}: \alpha_{1} \neq \alpha_{2} \neq \alpha_{3} \neq 0$, showing existence of co-integration. The study then compares the estimated F-statistic with the critical values suggested by M. H. Pesaran et al. (2001). If for example, F-statistic $<I(0)$, we accept the null hypothesis of no co-integration. However, if F-statistic > I(1), in this case we are bound to accept the alternative hypothesis, that is, long-run co-integration exist among the variables. And if estimated F-statistic lies between the suggested critical values of $I(0)$ and $I(1)$, our result will be inconclusive. Second, estimate of long run co efficient is obtained by using Akaike Information Creterion (AIC) and Schwarz Creterion (SBC). To verify convergence towards steady state equilibrium, we estimate short term elasticities by estimating ErrorCorrection Mechanism (ECM) given as under:

$$
\Delta \ln C_{t}=\beta_{0}+\beta_{1} \operatorname{Re} g+\sum_{i=1}^{p} \beta_{2} \Delta \ln C_{t-i}+\sum_{i=1}^{p} \beta_{3} \Delta \ln P_{t-i}+\phi E C M_{t-1}+\mu_{t}
$$


Journal of Applied Economics and Business Studies, Volume. 4, Issue 4 (2020) 161-186 https://doi.org/10.34260/jaebs.448

In the above equation (4), the coefficient of lag ECM shows adjustment factor towards long-run equilibrium when disequilibrium or shock occur in the short-run. Finally, to see over all fitness of the model, the study conduct diagnostic tests. For example, for checking serial correlation, the study uses LM test. Similarly, to check heteroscedasticity, we use Bresh-Pagan- Godfrey test. And for stability of the model, we use Cumulative Sum of Recursive Residuals (CUSUM) line. If CUSUM line lies within the boundaries of $5 \%$ significance level, it would indicate that our model is stable.

\section{Results and Discussion}

Table 5.1 Descriptive Statistics

\begin{tabular}{llllll}
\hline & $\ln ($ Cig Con) & $\ln ($ Cig Pr) & Ln(Real Inc) & $\ln ($ P Edu) & $\ln ($ Uni Edu) \\
\hline Mean & 10.75 & 2.40 & 10.68 & 16.37 & 12.27 \\
\hline Median & 10.77 & 2.21 & 10.66 & 16.48 & 11.55 \\
\hline Max & 11.23 & 4.18 & 11.03 & 16.95 & 14.28 \\
\hline Min & 10.27 & 1.17 & 10.31 & 15.52 & 10.66 \\
\hline Std. Dev & 0.29 & 0.86 & 0.19 & 0.42 & 1.33 \\
\hline Skew & -0.09 & 0.48 & -0.10 & -0.58 & 0.36 \\
\hline Kurt & 1.59 & 2.27 & 2.19 & 2.13 & 1.45 \\
\hline J-Bera & 3.20 & 2.31 & 1.10 & 3.33 & 4.65 \\
\hline Prob & 0.20 & 0.32 & 0.58 & 0.19 & 0.10 \\
\hline Obs & 38 & 38 & 38 & 38 & 38 \\
\hline
\end{tabular}

Above table 5.1 shows descriptive statistics of the included variables. All variables are log-transformed. Since coefficients of log transformed are directly interpreted in percentage, hence, it makes the data more easily interpretable. In addition, the log transformed data produce more stable variances of time series (Li et al., 2017). Based on the probability value of Jarque-bera, and the associated values of Skewness and Kurtosis, we reject the null hypothesis that all included variables are not normally distributed. Since, all the included variables are normally distributed, the study therefore, formally estimate the ARDL equation (3) to calculate cigarette price elasticities with and without regulations on smoking. However, before estimating elasticities, we apply Augmented Dickey-Fuller (ADF) test, to see whether data series are stationary or non-stationary. Below, table (1) shows results of the ADF test, indicating that none of the variables are stationary at level with intercept. However, by taking first difference, all series become stationary. Interestingly, none of the series have integration order (2) or above, we therefore, are justified in using the ARDL estimation method.

Table 5.2 ADF Unit Root Test

\begin{tabular}{lllll}
\hline \multicolumn{2}{c}{ At level (Intercept and Trend) } & \multicolumn{2}{c}{$\begin{array}{c}\text { At First Difference } \\
\text { (Intercept and trend) }\end{array}$} \\
\hline Variables & T-statistics & P-value & T-statistics & P-value \\
\hline \multicolumn{1}{c}{ Cig. Consumption } & -1.2085 & 0.6601 & -7.3369 & 0.0000 \\
\hline Cig. Price & -0.2641 & 0.9731 & -4.9628 & 0.0003 \\
\hline Real Income & -0.3422 & 0.9085 & -3.6127 & 0.0104 \\
\hline Primary Education & -1.9423 & 0.6134 & -4.2038 & 0.012 \\
\hline
\end{tabular}


Assad Ullah Khan and Anwar Shah

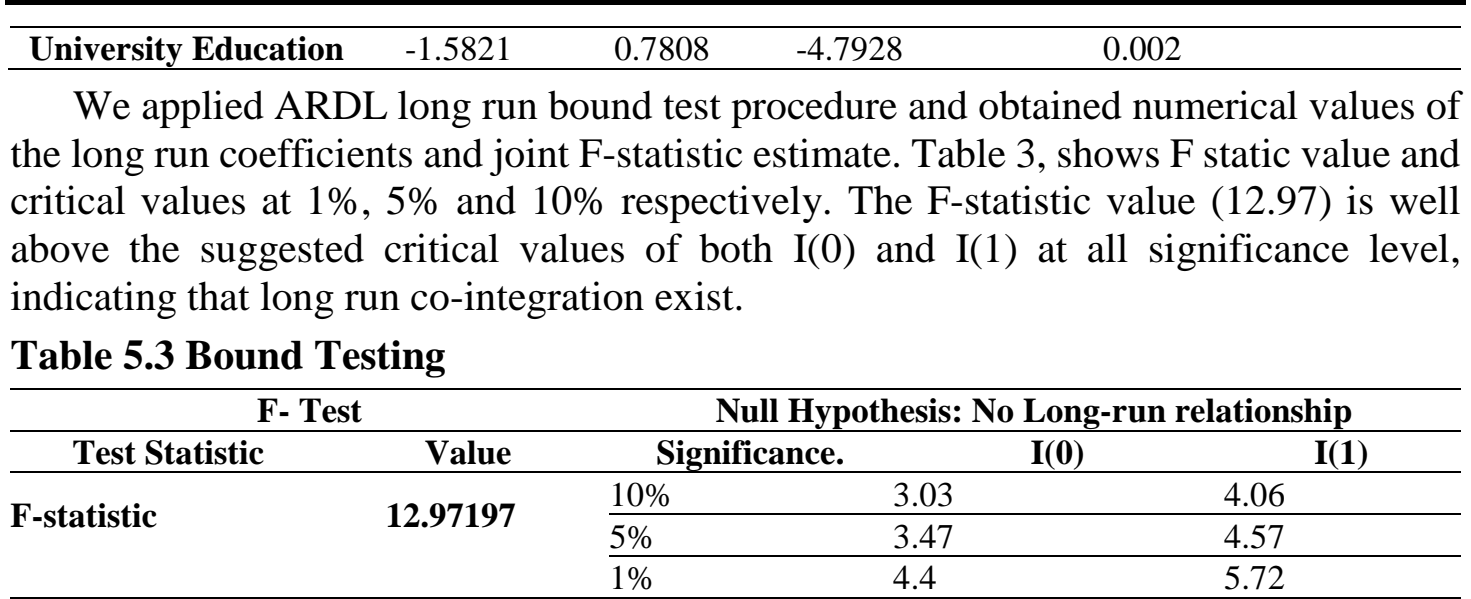

Below table 4, shows long-run estimates of ARDL. As evident from the table, cigarette prices negatively and significantly affect cigarette demand in the long-run. More specifically, coefficient of cigarette price which is -0.69 , indicating that cigarette demand decreases by $6.9 \%$ to a $10 \%$ increase in cigarette prices. This finding shows that cigarette demand model in Pakistan is in-elastic. Our result is inconsistent with Mushtaq et al. (2011), which shows an elastic cigarette demand model $(\ln P=-1.173)$. However, it is possible that Mushtaq et al. (2011) may have overestimated the price elasticity of cigarette demand. To examine this, we re-estimated cigarette demand model without government regulations. The result confirms upward bias in Mushtaq et al. (2011), that is, we obtained price elasticity equal to -1.22 . The study concludes that regressing cigarette consumption on cigarette prices only gives upward bias in the estimation of cigarette price elasticity. To accurately measure price elasticity of cigarette, we need to include all relevant determinants of cigarette consumption including regulations on cigarette smoking.

Table 5.4 Long Run ARDL Estimates

\begin{tabular}{lclll}
\hline Variables & Coefficients & Std. Error & t-Statistic & Prob \\
\hline Ln Cig. Price & $-0.69 * *$ & 0.27 & -2.57 & 0.02 \\
\hline Ln Real Income & $-3.88 * * *$ & 0.93 & -4.20 & 0.00 \\
\hline Reg*In Price & $-0.50 *$ & 0.28 & -1.82 & 0.08 \\
\hline Reg*InIncome & $3.98 * * *$ & 1.25 & 3.18 & 0.00 \\
\hline
\end{tabular}

$* * *, * *$ and $*$ Indicate $1 \%, 5 \%$ and $10 \%$ significance levels

Below table 5, shows short-run effects of variables on cigarette demand. Signs of both short -run and long-run coefficients are almost same, however, the short run estimates are smaller in magnitude. That is, the short-run cigarette price elasticity $(50 \%)$ is smaller than long-run (69\%). Table 4, shows that when cigarette prices are increased by $10 \%$, smoking will decreased by almost $5 \%$ in the short run. This indicates that compare to short run we can substantially decrease smoking in the long run. The lagged ECM coefficient $\left(E C M_{t-1}\right)$ is given in the last row of table (5). The ECM coefficient is 
Journal of Applied Economics and Business Studies, Volume. 4, Issue 4 (2020) 161-186 https://doi.org/10.34260/jaebs.448

negative and statistically significant at all levels. The negative and significant $E C M_{t-1}$ verifies that long run relationship exist among variables. The negative coefficient of $E C M_{t-1}(-0.72)$, indicates that every next year $72 \%$ shocks of the last year are adjusted back to the long run equilibrium.

In addition, the interactive term "Reg*lnPrice" show negative and statistically significant effect on cigarette consumption. The interactive term indicates that cigarette consumption decreases by $50 \%$ higher when regulation on smoking are imposed along with the increase in cigarette prices. However, interactive term "Reg*ln Income" is insignificant. This result indicates that the effect of income on cigarette consumption does not depend on smoking regulations. That is, the magnitude of income effect on cigarette consumption will not change even if regulation are imposed.

Table 5.5 Estimates of Error Correction Model

\begin{tabular}{lllll}
\hline Variables & Coefficients & Std. Errors & t-Statistic & P-value \\
\hline $\mathrm{C}$ & $37.26 * * *$ & 8.42 & 4.42 & 0.00 \\
\hline$\Delta \ln ($ Cig Cons) & $-0.36 *$ & 0.19 & -1.88 & 0.07 \\
\hline$\Delta \ln ($ Cig. Price) & $-0.50 * *$ & 0.19 & -2.64 & 0.01 \\
\hline$\Delta \ln (\mathbf{R}$. Income) & $-2.81 * * *$ & 0.75 & -3.73 & 0.00 \\
\hline$\Delta(\mathbf{R e g}$ InPrice) & $-0.36 *$ & 0.19 & -1.88 & 0.07 \\
\hline$\Delta($ Reg*In(R.income) & $2.89 * * *$ & 0.82 & 3.52 & 0.00 \\
\hline Ordinance 2002 & $-29.99 * * *$ & 8.39 & -3.57 & 0.00 \\
\hline ECM (-1) & $-0.72 * * *$ & $\mathbf{0 . 0 8 4}$ & $\mathbf{- 8 . 5 9}$ & $\mathbf{0 . 0 0}$ \\
\hline
\end{tabular}

Note: $* * *, * *$ and $*$ Indicates $1 \%, 5 \%$ and $10 \%$ significance levels respectively.

Furthermore, we see that regulations on smoking have negative and significant association with the cigarette consumption. The result obtained shows that cigarette consumption decreases by 29.99 million sticks when regulations on cigarette smoking are imposed by the government. This clearly indicates that beside cigarette price (taxation), regulations on smoking like health warnings, restriction on advertising and promotion of cigarette etc. significantly reduces cigarette smoking. This finding is consistent with (Cetin, 2017; Saffer \& Chaloupka, 2000; Wasserman et al., 1991).

The coefficient of income is although significant but negatively associated with cigarette consumption. Income elasticity indicates that cigarette consumption decrease by $2.8 \%$ and $3.9 \%$, in the short-run and long-run respectively, to a response of $1 \%$ increase in income. This finding is inconsistent with the empirical evidence from other studies on developing economies (see: Cetin, 2017; Siman et al., 2020; Tansel, 1993). However, evidence from develop countries also show a negative relationship of income with the cigarette demand (see: Koffarnus et al., 2015). The negative association of income with cigarette demand could be justified on the ground that as individual real income increases, living standard and therefore, awareness about health hazard 
increases. When awareness about the negative health consequence of smoking increases, individuals respond to it by reducing cigarette consumption.

We conduct several diagnostic tests and report the results below in table (6). More specifically, we conduct LM test to check whether errors are serially correlated. The study also checked whether errors have normal distribution and constant variances. The statistics obtained, indicated that errors have normal distribution and have no serial correlation. Furthermore, the result indicated no evidence of heteroscedasticity, that is, errors have constant variances.

Table 5.6 Model Diagnostic Tests

\begin{tabular}{lccc}
\hline \multicolumn{4}{l}{ Breusch-Godfrey Serial Correlation LM Test: } \\
\hline F-statistic & 1.655597 & Prob. F & 0.2098 \\
\hline Obs*R-squared & 4.041878 & Prob. Chi-Square & 0.1325 \\
\hline Heteroskedasticity Test: & Breusch-Pagan-Godfrey & \\
\hline F-statistic & 1.445588 & Prob. F & 0.2257 \\
\hline Obs*R-squared & 9.570956 & Prob. Chi-Square & 0.2142 \\
\hline
\end{tabular}

In addition to the diagnostic tests, the study checked whether model's parameters are stable. To observe this, the study used Cumulative Sum of Recursive Residuals (CUSUM) line. The graph shows that the CUSUM line lies inside 5\% significance boundaries. The CUSUM line indicated that model's parameters are stable.

\section{Figure 2 Plot of Cumulative Sum of Recursive Residuals}

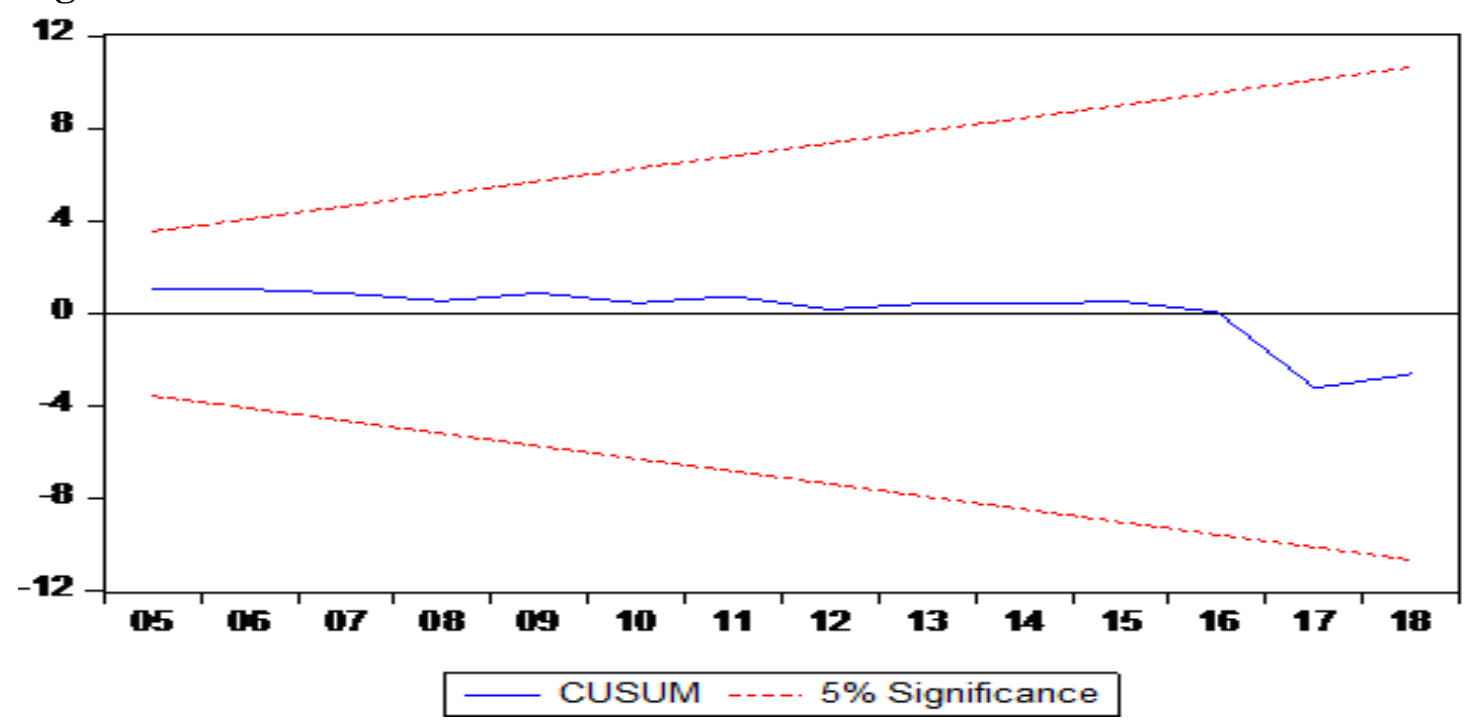

By estimating equation (4), we are able to test the hypothesis that whether various government SROs (anti-smoking policies) are helpful in reducing cigarette smoking. In addition, we also investigate that whether our national educational policies properly convey anti-smoking message to the youth of our country. We therefore, examines long run and short run relationships (scenario I and II respectively) among variables in different models. In the first scenario, we examines that whether government ordinance 
Journal of Applied Economics and Business Studies, Volume. 4, Issue 4 (2020) 161-186 https://doi.org/10.34260/jaebs.448

2002 and various SROs have significantly affected cigarette smoking. In the second scenario, we investigate that whether our educational institutions convey anti-smoking message to students. Using this strategy, we examines nine (9) different cigarette demand models under two different scenarios. The study uses dummy variables to examine the effects of non-price regulations (Ordinance and SROs) on cigarette smoking. Below, table (5.7) and (5.8) show long run and short run empirical results of included variables in (5) different models under the scenario (I).

In the first scenario, the study finds that cigarette prices, across all models (equations) both in the short run and long run, are negatively and significantly associated with cigarette consumption. More specifically, cigarette price elasticities are higher in the long run (varies from -0.79 to -0.96 ) than the short run (varies from -0.42 to -0.57 ). The result finds indicate that cigarette prices (tax on cigarettes) is an important determinant of cigarette demand that play a more significant role in reducing cigarette smoking in the long run. In the same line, real income has negative and statistically significant effects on cigarette demand across all equations (except few models) of the first scenario. This shows that wealthy individuals avoids risky behavior like cigarette smoking.

Results of table (5.8) shows that in the short run government Ordinance 2002 and all SROs have negative and statistically significant effects on cigarette smoking. The estimated value of the effects of non- price regulations on cigarette demand varies in magnitude from -21.62 (million sticks) to -40.09 (million sticks). In the long run only Ordinance 2002 and SRO 2003 (Restriction on cigarette advertisement) have negative and statistically significant effects on cigarette smoking (as shown in table 7). This clearly indicates that government non-price anti-smoking policies are more effective in the immediate period. For long run dynamic effect of non-price cigarette regulations, the government of Pakistan will have to pursue and monitor its proper implementation.

In the second scenario, the study test the hypothesis that whether national educational institutions of Pakistan properly convey anti-smoking education (awareness) among students. The study proxy national educational level with total enrollment in primary school and total enrollment of students in Pakistani universities. Model (2) and (3) of the scenario II, regress cigarette consumption on primary and university educational level along with price and income variable. However, model (4) and (5) further includes regulation Ordinance 2002 beside primary and university educational level. Empirical results of educational level in both primary school and universities are shown below in table (5.9) and (5.10), under the scenario II. Throughout the second scenario and across all models, the study finds very interesting and consistent results. The result obtained shows that both primary and university educational levels are significantly associated with cigarette consumption. Although primary educational level shows negative effect on cigarette consumption, however, on the contrary university education has positive effect on cigarette smoking. The result obtained indicates that cigarette smoking increases with the increase of enrollment in Pakistani 
universities. This further highlight the fact that university education, in Pakistan, do not properly convey anti-smoking message to students. The reason for the positive outcome could be that students in university are far away from parental affluence (home restrictions on smoking). Second, in university usually peer pressure (friends and classmates) influence students towards risky behavior like cigarette smoking and alcohol use. This finding of positive association between university education and cigarette smoking is consistent with (Wechsler et al., 1998; Yuanliang \& Zongyi, 2005).

Table 5.7 Long Run Estimates of ARDL

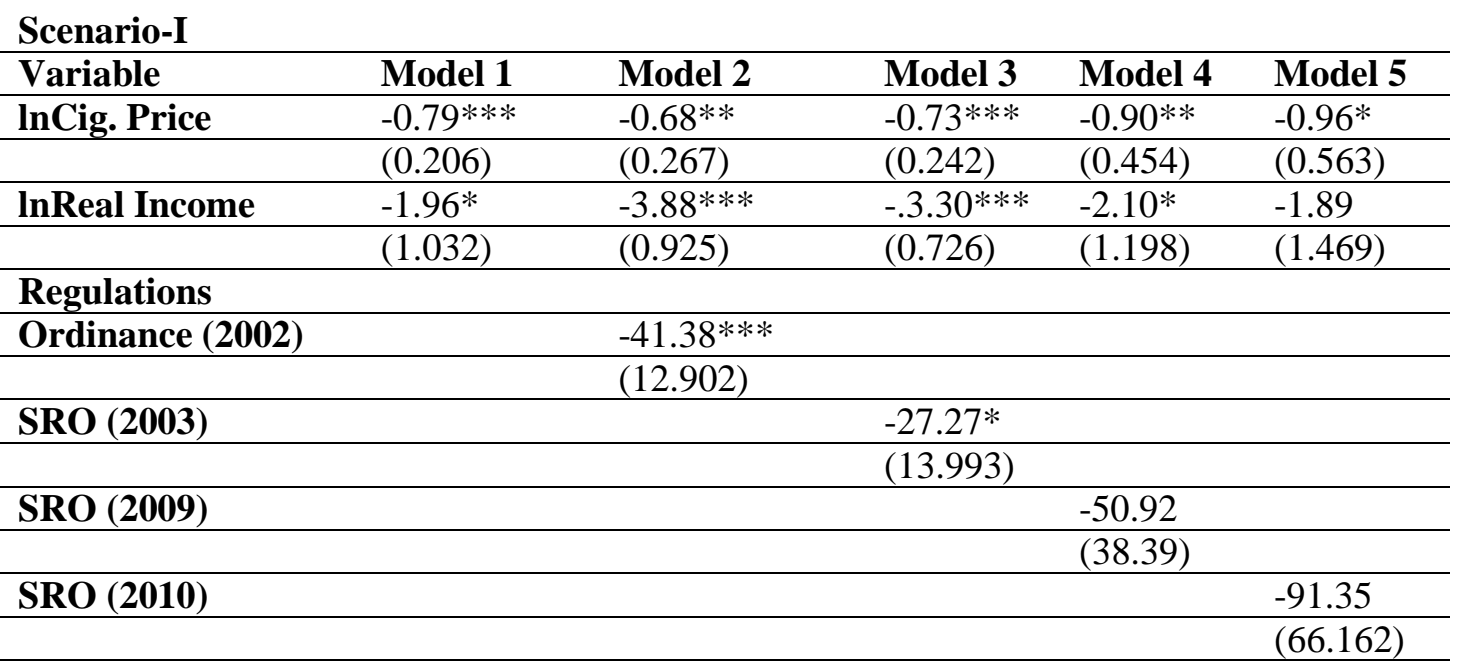

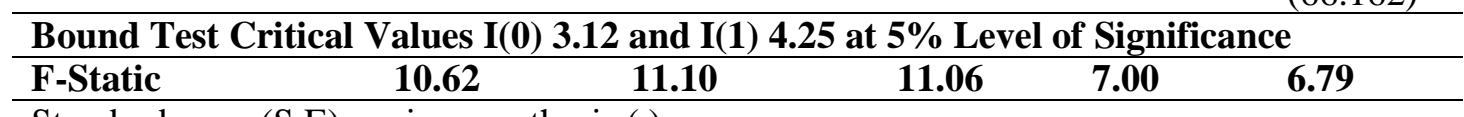

Standard error (S.E) are in parenthesis ( ).

$* * *, * *$, and $*$ represent coefficient significant at $1 \%, 5 \%$, and $10 \%$ respectively.

Table 5.8 Short Run Estimates of ARDL

Scenario-I

\begin{tabular}{|c|c|c|c|c|c|}
\hline Variables & Model 1 & Model 2 & Model 3 & Model 4 & Model 5 \\
\hline \multirow[t]{2}{*}{ Cons } & $18.82 * *$ & $37.26 * * *$ & $36.03 * * *$ & $17.46^{* *}$ & $14.07 *$ \\
\hline & $(8.343)$ & $(8.423)$ & $(8.231)$ & $(8.255)$ & $(8.521)$ \\
\hline \multirow[t]{2}{*}{$\Delta \ln ($ Cig. Price $)$} & $-0.47 * * *$ & $-0.49 * *$ & $-0.57 * * *$ & $-0.47 * *$ & $-0.42 * *$ \\
\hline & $(0.106)$ & $(0.179)$ & $(0.178)$ & $(0.208)$ & $(0.210)$ \\
\hline \multirow[t]{2}{*}{$\Delta \ln ($ Real Income $)$} & -1.17 & $-2.81 * * *$ & $-2.61 * * *$ & -1.10 & -0.87 \\
\hline & $(0.723)$ & $(0.753)$ & $(0.714)$ & $(0.719)$ & $(0.737)$ \\
\hline \multicolumn{6}{|l|}{ Regulations) } \\
\hline \multirow[t]{2}{*}{ Ordinance (2002) } & & $-29.89 * * *$ & & & \\
\hline & & $(8.392)$ & & & \\
\hline \multirow[t]{2}{*}{ SRO (2003) } & & & $-21.62 * *$ & & \\
\hline & & & $(10.164)$ & & \\
\hline \multirow[t]{2}{*}{ SRO (2009) } & & & & $-26.63 *$ & \\
\hline & & & & $(15.63)$ & \\
\hline SRO (2010) & & & & & $-40.09 * *$ \\
\hline
\end{tabular}

180 
Journal of Applied Economics and Business Studies, Volume. 4, Issue 4 (2020) 161-186 https://doi.org/10.34260/jaebs.448

\begin{tabular}{llllll}
$\mathbf{E C M}$ term(-1) & $-0.59 * * *$ & $-0.72 * * *$ & $-0.52 * * *$ & $-0.43 * * *$ & $-0.79 * * *$ \\
\hline & $(0.102)$ & $(0.080)$ & $(0.075)$ & $(0.063)$ & $(0.089)$ \\
\hline
\end{tabular}

Standard error (S.E) are in parenthesis ( ).

$* * *, * *$, and $*$ represent coefficient significant at $1 \%, 5 \%$, and $10 \%$ respectively.

Table 5.9 Long Run ARDL Estimates

Scenario-II

\begin{tabular}{|c|c|c|c|c|}
\hline Variable & Model 1 & Model 2 & Model 3 & Model 4 \\
\hline \multirow[t]{2}{*}{ In Cig. Price } & $-1.08 * * *$ & $-0.76^{* *}$ & $-0.49 *$ & $-0.98 * *$ \\
\hline & $(0.238)$ & $(0.135)$ & $(0.288)$ & $(0.232)$ \\
\hline \multirow{2}{*}{ In Real Income } & -0.97 & $-1.70 * *$ & $-.3 .32 * * *$ & $-3.36 * * *$ \\
\hline & $(1.02)$ & $(0.701)$ & $(0.988)$ & $(0.827)$ \\
\hline \multirow[t]{2}{*}{ In Primary Education } & $-1.00 * *$ & & $-1.03 *$ & \\
\hline & $(0.400)$ & & $(0.596)$ & \\
\hline \multirow[t]{2}{*}{ In University Education } & & $0.20 * * *$ & & $0.22 * *$ \\
\hline & & $(0.061)$ & & $(0.119)$ \\
\hline \multicolumn{5}{|l|}{ Regulations } \\
\hline \multirow[t]{2}{*}{ Ordinance (2002) } & & & $-44.78 * * *$ & $-31.24 * * *$ \\
\hline & & & $(13.632)$ & $(11.619)$ \\
\hline \multicolumn{5}{|c|}{ Bound Test Critical Values I(0) 2.87 and I(1) 4.00 at $5 \%$ Level of Significance } \\
\hline F-Static & 11.39 & 11.82 & 10.97 & 10.85 \\
\hline
\end{tabular}

Standard error (S.E) are in parenthesis ( ).

$* * *, * *$, and $*$ represent coefficient significant at $1 \%, 5 \%$, and $10 \%$ respectively.

Table 5.8 Short Run ARDL Estimates

\begin{tabular}{|c|c|c|c|c|}
\hline Variables & Model 1 & Model 2 & Model 3 & Model 4 \\
\hline \multirow[t]{2}{*}{ Cons } & $23.32 * * *$ & $21.65 * * *$ & $41.49 * * *$ & $34.62 * * *$ \\
\hline & $(7.789)$ & $(7.599)$ & $(8.336)$ & $(8.201)$ \\
\hline \multirow[t]{2}{*}{$\Delta \ln ($ Cig. Price) } & $-0.67 * * *$ & $-0.62 * * *$ & $-0.33^{*}$ & $-0.47 * *$ \\
\hline & $(0.122)$ & $(0.109)$ & $(0.199)$ & $(0.181)$ \\
\hline \multirow[t]{2}{*}{$\Delta \ln ($ Real Income $)$} & -0.61 & $-1.38 * *$ & $-2.44 * * *$ & $-2.71 * * *$ \\
\hline & $(0.692)$ & $(0.697)$ & $(0.776)$ & $(0.724)$ \\
\hline \multirow[t]{2}{*}{$\Delta \ln ($ Primary Edu $)$} & $-0.62 * *$ & & $-0.69 *$ & \\
\hline & $(0.230)$ & & $(0.358)$ & \\
\hline \multirow[t]{2}{*}{$\Delta \ln ($ University Edu) } & & $0.16 * * *$ & & $0.22 *$ \\
\hline & & $(0.059)$ & & $(0.119)$ \\
\hline \multicolumn{5}{|l|}{ Regulations) } \\
\hline \multirow[t]{2}{*}{ Ordinance (2002) } & & & $-30.22 * * *$ & $-25.19 * * *$ \\
\hline & & & $(8.018)$ & $(8.446)$ \\
\hline \multirow[t]{2}{*}{ ECM term (-1) } & $-0.66 * * *$ & $-0.80 * * *$ & $-0.67 * * *$ & $-0.80 * * *$ \\
\hline & $(0.067)$ & $(0.112)$ & $(0.069)$ & $(0.083)$ \\
\hline
\end{tabular}

Standard error (S.E) are in parenthesis ( ).

$* * *, * *$, and $*$ represent coefficient significant at $1 \%, 5 \%$, and $10 \%$ respectively.

\section{Conclusion and Recommendations:}

From the estimated model of the study we concludes, that beside cigarette taxation, regulations on smoking play a significant role in reducing cigarette consumption. However, in Pakistan, research concerning the effects of smoking-regulation on cigarette demand is missing. Therefore, this study is an attempt to examine whether non- 
price regulations on smoking, in Pakistan, are helpful in reducing cigarette demand over the period 1981-2018. The findings of this study confirm the hypothesis that regulations on smoking are playing highly significant and quite effective role in limiting cigarette demand. Furthermore, the estimated price elasticities are 5\% in the short-run and $6.9 \%$ in the long run. This show that demand for cigarette smoking, in Pakistan, is in-elastic.. Beside, enrollment in universities has positive effects on cigarette. That is, cigarette smoking increases with the increase of enrollment in university education. This is alarming and show that education at university level do not educate students about the danger of cigarette smoking. Based on findings of the study, following major policy suggestions are recommended.

First, empirical findings of this study is evident of the fact that regulations on cigarette smoking have negative but highly significant impact on the demand for cigarette consumption. Regulations on smoking is more effective policy as it is generally applicable to all brands of cigarette. Therefore, to reduce cigarette consumption, Pakistan will have to announce and ensure implementation of stronger, more comprehensive and better enforced regulations on cigarette smoking.

Second, although price and real income both are negatively associated with cigarette consumption. However, cigarette affordability in terms of real income has also increased. Therefore, to further discourage smoking, the study recommends to the government to increase tobacco taxes to make cigarettes less affordable.

Third, as university education is positively associated with cigarette consumption. This means that national educational policies do not properly convey the message that smoking causes negative health consequences. Therefore, the study recommends that seminars should be arranged at university level which disseminate information about the negative effects of smoking on health.

Although, this study analyzes important determinants which play significant role in reducing cigarette demand. However, there are few limitations of this study as well. Fist, tobacco companies usually manipulate the actual data. For example tax on cigarette is an important determinant of cigarette demand, however, illicit cigarette production tactics are used by tobacco companies to minimize the role of taxes in limiting cigarette sale. However, the study is limited by the availability of illicit cigarette production data.

Second, in Pakistan, large number of cigarettes sale is unreported, therefore the calculated cigarette price elasticity in this study may be overstated. When price of taxable cigarettes increases, individual might shift to unreported or non-custom (smuggling cigarette) cigarette consumption. Therefore, it is possible that the estimated price elasticity may not have reflected the actual decline in cigarette consumption. Again, this study is limited by the availability of unreported or illegal cigarette consumption data. However, unlike other studies conducted in Pakistan, this study beside cigarette prices have analyzed the role of non- price regulations on smoking. Since, regulations on smoking are generally applicable on all types of cigarettes 
Journal of Applied Economics and Business Studies, Volume. 4, Issue 4 (2020) 161-186 https://doi.org/10.34260/jaebs.448

(reported or unreported), we therefore, have made efforts to actually show the decline in cigarette smoking as a result of both cigarette price and regulations on smoking. Third, the study is limited by analyzing the role of religion in reducing cigarette consumption. Pakistan is a majority Muslim populated country and the Religion "Islam" promotes good health of human being. Islam forbids every addicted and bad goods like use of alcohol and cigarette smoking. However, the study is limited by the availability of data to empirically examine the role of religion on cigarette smoking.

\section{References}

Ahsan, M., Saad, M., Jawed, M., Akhtar, S., Haseeb, A., Bilal, M., \& Ahmed, A. (2015). Impact of tobacco health warnings on smokers in Pakistan. Journal of the Pakistan Medical Association, 66(1), 59-62.

Alam, A. Y., Iqbal, A., Mohamud, K. B., Laporte, R. E., Ahmed, A., \& Nishtar, S. (2008). Investigating socio-economic-demographic determinants of tobacco use in Rawalpindi, Pakistan. BMC Public Health, 8, 1-9. https://doi.org/10.1186/14712458-8-50

Blecher, E. (2008). The impact of tobacco advertising bans on consumption in developing countries. Journal of Health Economics, 27(4), 930-942. https://doi.org/10.1016/j.jhealeco.2008.02.010

Burki, S., Pasha, A., Pasha, H., John, R., Jha, P., Baloch, A., Kamboh, G., Cherukupalli, R., \& Chaloupka, F. (2013). The economics of tobacco and tobacco taxation in Pakistan. content/uploads/2014/05/PakistanReport_May2014.pdf

https://tobacconomics.org/wp-

Cetin, T. (2017). The effect of taxation and regulation on cigarette smoking: Fresh evidence from Turkey. Health Policy, 121(12), 1288-1295. https://doi.org/10.1016/j.healthpol.2017.09.015

Chaloupka, F. J., \& Warner, K. E. (2000a). Chapter 29 The economics of smoking. In Handbook of Health Economics. https://doi.org/10.1016/S1574-0064(00)80042-6

Chaloupka, F. J., \& Warner, K. E. (2000b). The economics of smoking. Handbook of Health Economics, 1, 1539-1627.

Del Carmen, G., Fuchs, A., \& Genoni, M. E. (2018). The Distributional of Impacts of Cigarette Taxation in Bangladesh. In The Distributional of Impacts of Cigarette Taxation in Bangladesh. World Bank. https://doi.org/10.1596/30011

Emmanuel Guindon, Arindam Nandi, Frank Chaloupka, P. J. (2011). Why India should increase taxes on cigarettes | VOX, CEPR Policy Portal. https://voxeu.org/article/why-india-should-increase-taxes-cigarettes

FCTC, W. (2015). The WHO Framework Convention on Tobacco Control: an overview Background.

Fuji, E. T. (1980). The demand for cigarettes: further empirical evidence and its implication for public policy. Applied Economics, 12, 479-489. 
Graham, K. M. (2013). Eating on an interconnected planet. Environmental Research Letters.

Hu, T. W., \& Mao, Z. (2002). Chinese Economy. China Report, 2(6), 8-12. https://doi.org/10.1177/000944556600200602

Jha, P., \& Chaloupka, F. (1999). Curbing the epidemic. Governments and the Economics of Tobacco Control. Washington (DC): The World Bank.

John, R. M. (2008). Price elasticity estimates for tobacco products in India. Health Policy and Planning, 23(3), 200-209. https://doi.org/10.1093/heapol/czn007

Koffarnus, M. N., Wilson, A. G., \& Bickel, W. K. (2015). Effects of experimental income on demand for potentially real cigarettes. Nicotine and Tobacco Research, 17(3), 292-298. https://doi.org/10.1093/ntr/ntu139

Li, X., Fan, Y., \& Wu, L. (2017). CO2 emissions and expansion of railway, road, airline and in-land waterway networks over the 1985-2013 period in China: A time series analysis. Transportation Research Part D: Transport and Environment, 57, 130140. https://doi.org/10.1016/j.trd.2017.09.008

Marzioni, S., Pandimiglio, A., \& Spallone, M. (2020). Excise gap and price in the Italian cigarette industry. Applied Economics. https://doi.org/10.1080/00036846.2020.1733480

Mushtaq, N., Mushtaq, S., Beebe, L. A., Mushtaq, N., Mushtaq, S., \& Beebe, L. A. (2011). Economics of tobacco control in Pakistan: estimating elasticities of cigarette demand Stable URL : http://www.jstor.com/stable/41320190 Economics of tobacco control in Pakistan : estimating elasticities of cigarette demand. 20(6), 431-435.

Nayab, D., Nasir, M., Memon, J. A., Khalid, M., \& Hussian, A. (2018). Economics of Tobacco Taxation and Consumption.

Nelson, J. P. (2003). Contributions to Economic Analysis \& Policy Cigarette Demand, Structural Change, and Advertising Bans: International Evidence, Cigarette Demand, Structural Change, and Advertising Bans: International Evidence,.

Nizami, S., Sobani, Z., Raza, E., Baloch, N.-U.-A., \& Khan, J. (2011). Causes of smoking in Pakistan : an analysis of social factors. Journal of the Pakistan Medical Association, 61(2), 198-201.

Ouattara, B. (2004). www.econstor.eu.

Pesaran, H., \& Shin, Y. (1999). An Autoregressive Distributed Lag Modelling Approach to Cointegration "chapter 11. Econometrics and Economic Theory in the 20th Century: The Ragnar Frisch Centennial Symposium.

Pesaran, M. H., \& Pesaran, B. (1997). Microfit 4.0: Interactive econometric analysis. Oxford University Press.

Pesaran, M. H., Shin, Y., \& Smith, R. J. (2001). Bounds testing approaches to the 
Journal of Applied Economics and Business Studies, Volume. 4, Issue 4 (2020) 161-186 https://doi.org/10.34260/jaebs.448 analysis of level relationships. Journal of Applied Econometrics, 16(3), 289-326.

Randell, M. (2018). Australia can help Indonesia kick the habit - Australia-Indonesia Centre. Australia-Indonesia Centre.

Rasool, A., Ahmad, S., Farooq, U., Rasool, M., Shah, Z., Hammad, M., Utmanzai, A., Wahab, F., Sadique, I., \& Ahmad, J. (2011). Compliance of anti-smoking regulations by cigarette industry in Pakistan. Journal of Ayub Medical College, Abbottabad: JAMC, 23(3), 94-96.

Ross, H., \& Al-Sadat, N. A. M. (2007). Demand analysis of tobacco consumption in Malaysia. Nicotine and Tobacco Research, 9(11), 1163-1169. https://doi.org/10.1080/14622200701648433

Saffer, H., \& Chaloupka, F. (2000). PII: S0167-6296(00)00054-0 2011070814815705.pdf. Health Economics 192000 1117-1137, 1124. http://storage.globalcitizen.net/data/topic/knowledge/uploads/2011070814815705 .pdf

Siman, S., Tawakal, M. A., Risamasu, P. I. M., \& Kadir, R. (2020). Effect of household size, working hours, health and income on consumption expenditure of poor household. Enfermeria Clinica, 30, 512-515. https://doi.org/10.1016/j.enfcli.2019.10.131

SPDC. (2018). Macroeconomic impacts of tobacco Use in Pakistan. December. https://doi.org/10.13140/RG.2.2.12229.81128

Stoklosa, M., Drope, J., \& Chaloupka, F. J. (2016). Prices and e-cigarette demand: Evidence from the European Union. Nicotine and Tobacco Research. https://doi.org/10.1093/ntr/ntw109

Tansel, A. (1993). Cigarette demand, health scares and education in Turkey. Applied Economics, 25(4), 521-529. https://doi.org/10.1080/00036849300000060

Teixeira, A. P. (2018). The Government Willingness to Legislate Tobacco Control and Government Income From Tobacco Taxes in Brazil. Journal of Global Oncology. https://doi.org/10.1200/jgo.18.94700

Walbeek, V. (2005). The economics of tobacco control in south africa. file://C:/Users/4staR/Downloads/thesis_com_2005_van_walbeek_c.pdf

Warner, K. E. (1981). The effects of the anti smoking campaign on cigarette consumption. American Journal of Public Health, 67(7), 645-650. https://doi.org/10.2105/AJPH.67.7.645

Wasserman, J., Manning, W. G., Newhouse, J. P., \& Winkler, J. D. (1991). The effects of excise taxes and regulations on cigarette smoking. Journal of Health Economics, 10(1), 43-64. https://doi.org/10.1016/0167-6296(91)90016-G

Wechsler, H., Rigotti, N. A., Gledhill-Hoyt, J., \& Lee, H. (1998). Increased levels of cigarette use among college students: A cause for national concern. Journal of the American Medical Association, 280(19), 1673-1678. 
https://doi.org/10.1001/jama.280.19.1673

WHO. (2015). WHO | Tobacco control in Pakistan. https://www.who.int/tobacco/about/partners/bloomberg/pak/en/

WHO. (2020). Tobacco. https://www.who.int/news-room/fact-sheets/detail/tobacco

Yuanliang, B., \& Zongyi, Z. (2005). Aggregate cigarette demand and regional differences in China. Applied Economics, 37(21), 2523-2528. https://doi.org/10.1080/00036840500358640 